\title{
The Nervous Mechanism of Sympathetic over Activity Induced by Chronic Intermittent Hypoxia
}

Qi An and En-Sheng Ji*

Department of Physiology, School of Basic Medicine, Hebei University of Traditional Chinese Medicine, China

\begin{abstract}
Hypertension is concerned to be a common complication in Chronic Intermittent Hypoxia (CIH) conditions which mimic the state of Obstructive Sleep Apnoea (OSA) in clinic. Sympathoexcitation is a crucial origin in the process of high blood pressure and the mechanisms involved in the sympathoexicitatory changes after $\mathrm{CIH}$ exposure are complex referring to chemoreflex, baroreflex, neurotransmitters, and central nuclei and so on. In this review we predominantly expound the effect of $\mathrm{ClH}$-induced potentiated Carotid Body (CB) chemoreceptor sensitivity to hypoxia stimulation which results in the enhancement of RSNA and Endothelin (ET) is mentioned due to its expression in CB and the fact that ET is thought to be a significant chemoreceptor-excitatory transmitter. Previously studies have shown expression of ET and ET receptors in the CB chemoreceptor glomus cells and vessel system, and ClH obviously increased the expression which indicated a possible effect of ET to the potentiated ventilatory and cardiovascular responses to acute hypoxia probably via increased inward $\mathrm{Ca}^{2+}$ currents, inflammatory response or Acid-Sensitive lon Channels (ASICs) in chemoafferent neurons in the petrosal ganglion. However we also display the effect of enhanced central respiratory-sympathetic coupling which also participated in the increase in sympathetic activity. The other mechanism introduced in this review is the role of the Nucleus Tractus Solitarius (NTS) after ClH exposure. Neurotransmitters like ET and Glutamate act on the cerebroventricle and the NTS elicit significantly increase of RSNA in CIH group. The sympathetic nerve originated site Rostral Ventrolateral Medulla (RVLM) also makes adaptive changes after CIH to copes the hypoxia stimulation and induces RSNA responses. At last we raise the phenomenon that depressed baroreflex sensitivity emerged after a long time $\mathrm{CIH}$ exposure and is involved in the process of sustained high blood pressure.
\end{abstract}

Keywords: Chronic intermittent hypoxia; Hypertension; Chemoreceptor-sensitivity; Sympathetic nerve activity

\section{Introduction}

Obstructive Sleep Apnoea (OSA), which was a common respiratory system disease, affects between $5 \%$ and $20 \%$ of the population with a high morbidity and mortality. Among all of these complications, hypertension has obtained more and more attention due to its complex mechanism which elucidating the procedure of increasing of artery pressure. A deal of laboratory focus on OSA-correlated hypertension used Chronic Intermittent Hypoxia ( $\mathrm{CIH}$ ) mimics the state of OSA, aimed at establishing integrity etiology of hyperpiesia consisting of central nervous system, vascular activity, neurotransmitter , and other influential factors. Protocols of $\mathrm{CIH}$ were developed by Fletcher, who exposed adult rats to 30 days of $\mathrm{CIH}$ during their sleep period and found a sustained increase in mean arterial pressure [1]. Fletcher et al. demonstrated that $\mathrm{CIH}$-induced sustained systemic hypertension was partly mediated by the sympathetic nervous system [2]. A study exposed healthy subjects between the ages of 20 and $34 \mathrm{yr}$ to 28 days of $\mathrm{CIH}$ showing an increased muscular sympathetic nerve activity and forearm vascular resistance, indicating a relationship between increased blood pressure following prolonged exposure to $\mathrm{CIH}$ in healthy humans and sympathetic activation and augmented forearm blood flow [3].

Renal Sympathetic Nerve Activity (RSNA) and baroreflex or chemoreflex sympathetic activity pertaining to central nervous system lay on a critical position with regard to hypertension; nevertheless its exact contribution is still equivocal and is required further investigation. Previous studies emerged variant consequence of SNA and reflexrelated SNA after CIH exposure, which alike or opposite. Therefore, we conclude all of these findings and observe their disparity, determine whether these diversities were based on variant species, experiment condition and other factors, compare different mechanisms in these studies. This will provide allround and intimate prehension for further research.

\section{Resting RSNA after CIH Exposure}

Exposure of rats to $\mathrm{CIH}$ increased arterial pressure combined with enhanced sympathetic nerve activity (SNA). Rats had higher SNA after exposure to $\mathrm{CIH}$ in anesthetic conditions compared with control rats $(1.9 \pm 0.2$ vs. $0.9 \pm 0.2 \mu \mathrm{V}, \mathrm{P}<0.05)$ [4]. Healthy humans subjects demonstrated an increase in mean muscle sympathetic nerve activity (MSNA) that was expressed as either burst frequency (bursts/ $\mathrm{min}$ ) or burst incidence (bursts $/ 100 \mathrm{hb}$ ) after $4 \mathrm{wk}$ of intermittent cyclic hypoxia [9.94 \pm 2.0 to $14.63 \pm 1.5$ bursts $/ \mathrm{min}(\mathrm{P}<0.05) ; 16.89 \pm 3.2$ to $26.97 \pm 3.3$ bursts $/ 100 \mathrm{hb}(\mathrm{P}=0.01)$ ] [3]. Study previously shown that sympathectomy chemically caused by $6-\mathrm{OH}$-dopamine prior to $\mathrm{CIH}$ restricted the increase in arterial pressure [5]. Bao et al. in another experiment observed similar results using renal sympathetic denervation [6]. Therefore, the integrity of the sympathetic nervous system to the kidneys was essential to the increase of arterial pressure in $\mathrm{CIH}$ rodents. Kumar et al. reported an enhanced secretion from adrenal medulla during hypoxia if only the rodents were prior exposure to $\mathrm{CIH}$ which indicating an augmented chemoreflex-sympathetic hypoxia sensitivity [7].

Guild et al. have pronounced another index of total sympathetic activity by administration of ganglionic blockade [8]. The fall in MAP in

*Corresponding author: En-Sheng Ji, Department of Physiology, School of Basic Medicine, Hebei University of Traditional Chinese Medicine, 326, Xinshi South Road, Shijiazhuang 050091, Hebei, P.R. China, Tel: +86 311 86265107; Fax: +86 311 86265174; E-mail: jejesphy50@gmail.com

Received December 27, 2013; Accepted January 27, 2014; Published January 30, 2014

Citation: An Q, Ji ES (2014) The Nervous Mechanism of Sympathetic over Activity Induced by Chronic Intermittent Hypoxia. J Pulm Respir Med 4: 170 doi:10.4172/2161-105X. 1000170

Copyright: ( $) 2014$ An Q, et al. This is an open-access article distributed under the terms of the Creative Commons Attribution License, which permits unrestricted use, distribution, and reproduction in any medium, provided the original author and source are credited. 
response to hexamethonium (a ganglionic blockade) after injection of losartan (AT1 receptor antagonist) was higher in $\mathrm{CIH}$ than in normoxic rats and the MAP was decreased to similar levels in both groups, despite the fact that losartan or hexamethonium alone produced no significant changes [9]. This indicated that the increase in baseline arterial pressure of $\mathrm{CIH}$ is maintenanced by an augmentation in sympathetic outflow to vascular beds.

\section{The Sympathetic Nerve Response to Acute Hypoxia after $\mathrm{CIH}$}

Several lines of evidence concerning the involvement of the sympathetic nervous system in the sustained hypertension after exposure to $\mathrm{CIH}$ observed in adult rats were definitely certified. The responsiveness of the sympathetic nerve activity to a new acute episode of hypoxia after exposure to $\mathrm{CIH}$ also demand completely characterized. Exposed 3-weeks-old rats to $\mathrm{CIH}$ conditions presented a significant increase in tSNA (thoracic Sympathetic Nerve Activity), frequency of the PND and a greater bradycardic in response to new chemoreflex activation by potassium cyanide [10].

\section{The Effect of Peripheral Chemoreflex Sympathoexcitation after CIH}

on

A potentiated sympathetic chemoreflex is a hallmark of exposure to $\mathrm{CIH}$ and has been attributed to enhanced responsiveness of carotid body afferents to the brain [11]. The increase of sympathetic nerve activity after $\mathrm{CIH}$ exposure was attenuated when the animals were prior undertook carotid sinus denervated [12]. Patients with OSA or exposure to $\mathrm{CIH}$, all could exhibit tonic chemoreflex activation which may enhance sympathetic activity and then induced increase in blood pressure [13]. It was introduced that the effects of $\mathrm{CIH}$ on the $\mathrm{CB}$ are similar to that of ischemia-reperfusion response in other tissue, which is characterized to enhance superoxide anion production and oxidative stress, since administration of superoxide scavenger could completely abolish the effects of CIH on CB afferent activity [14].

The mechanisms that involved in the augmented sympatheticchemoreflex hypoxic responses after $\mathrm{CIH}$ were complicated and referred to multiple modulators and pathways.

\section{The Role of ET-1 on Carotid Body Chemoreceptor}

Arterial chemoreceptors located in the aortic and CBs respond to hypoxemia and hypercapnia. CBs acted as a primarily component of chemoreflex response attracted greatest attention recently. Its potentiated chemosensory response to hypoxia was verified to contribute to the $\mathrm{CIH}$-induced hypoxic ventilatory and cardiovascular responses [15]. ET was confirmed to be the merely clearly excitatory peptide modulator of $\mathrm{CB}$ function [16]. ET-1 through two types of heptahelicoidal $G$ protein-coupled transmembrane receptors which were $\mathrm{ET}_{\mathrm{A}}-\mathrm{R}$ and $\mathrm{ET}_{\mathrm{B}}-\mathrm{R}$ [17].

Rey et al. [18] found a 10-fold increase of ET-1 immunoreactivity in the $\mathrm{CB}$ from $\mathrm{CIH}$ cats and administration of bosentan, ET receptor type $\mathrm{A}$ and $\mathrm{B}$ antagonists, significantly reduce the increased $\mathrm{CB}$ discharge and chemosensory responses to acute hypoxia [18]. The authors previously have confirmed that ET-1 immunoreactivity was found in blood vessels of the $\mathrm{CB}$ vascular pole, suggesting that ET-1 plays a relevant role in the regulation of the $\mathrm{CB}$ vascular tone [19]. Previously studies showing a relationship between ET-1 and CB oxygen-sensing process. In situ or vitro preparation, ET-1 generated a potent dosedependent chemosensory excitation [20]. Some literatures found that ET-1 was bound with ${ }^{125} \mathrm{I}$ in blood vessels and chemoreceptor (glomus) cells in rat and cat CBs [21]. Using immunohistochemistry method, Chen et al. also found the presence of $\mathrm{ET}_{\mathrm{A}} \mathrm{R}$ in rat glomus cells and interlobular vasculature and chronic sustained hypoxia increases ETlike immunoreactivity and $\mathrm{ET}_{\mathrm{A}}-\mathrm{R}$ expression in the rat $\mathrm{CB}$, accompanied with an augmented rat $\mathrm{CB}$ chemosensory response to acute hypoxia in a time-dependent manner and $\mathrm{ET}_{\mathrm{A}} \mathrm{-} \mathrm{R}$ antagonist $\mathrm{BQ}-123$ reversed this change [22]. Western Blot analysis showed a significant increase in $\mathrm{ET}_{\mathrm{B}}-\mathrm{R}$ expression in $\mathrm{CB}$ after 4 days exposure to $\mathrm{CIH}$, but with no differences in $\mathrm{ET}_{\mathrm{A}}-\mathrm{R}$ [23]. In this literature, the authors also used immunohistochemistry to determine that the $\mathrm{ET}_{\mathrm{A}}-\mathrm{R}_{\mathrm{B}}$ and $\mathrm{ET}_{\mathrm{B}}-\mathrm{R}$ staining were found in both control and $\mathrm{CIH}$-treated $\mathrm{CBs}$ while distributed differently. $\mathrm{ET}_{\mathrm{A}}-\mathrm{R}$ immunoreactivity was localized in the cytoplasm of TH-positive cells that the latter was a marker for glomus cells [24] but with no significance in both groups. However the $\mathrm{ET}_{\mathrm{B}}-\mathrm{R}$ was present a conspicuous increase in the glomus cells of the $\mathrm{CIH}$-treated group. They did not detect any qualitative difference in staining intensity of ETA-R and ETB-R within the blood vessels when we compared $\mathrm{CBs}$ from control and $\mathrm{CIH}$-treated cats. Double-positive staining for ET- 1 and TH was abundant within the cell clusters located in the CB parenchyma and scarce in the peripheral zones close to the vascular pole indicating that cat glomus cells express ET peptides in normoxia and after CIH exposure [24]. It is known that ETB-R increases nitric oxide (NO) synthesis through endothelial NO synthase upregulation. $\mathrm{NO}$ is a tonic inhibitory modulator of $\mathrm{CB}$ chemoreception. Gardner et al. found that the $\mathrm{ET}_{B}-\mathrm{R}$ agonist sarafotoxin $6 \mathrm{c}$ could dose-dependently inhibited high extracellular potassium- induced ATP release [25]. It is worth mentioning that ATP seems to be an excitatory neurotransmitter in the hypoxic response of the mammalian CB [26]. Therefore, ETB- $\mathrm{R}$ upregulation in the $\mathrm{CIH}$-exposed $\mathrm{CB}$ may be a compensatory inhibitory mechanism by increasing the NO synthesis and counteracting the chemoexcitatory effect of ET-1 [23].

Carotid body type 1 chemoreceptive cells displayed inward $\mathrm{Ca}^{2+}$ currents which induced an increase of $\left[\mathrm{Ca}^{2+}\right]_{i}$. Whole-cell patch clamp investigation revealed that the $\mathrm{Ca}^{2+}$ inward currents were potentiated in the presence of ET in normoxic condition [27]. Hypoxia-induced increase of intracellular $\mathrm{Ca}^{2+}$ levels was augmented after superfusion of ET. The role of ET in the potentiated inward $\mathrm{Ca}^{2+}$ currents was concerned to patiticipate in the process of phosphorylation of protein like $\mathrm{Ca}^{2+}$-channel protein. Type $1 \mathrm{O} 2$-sensitive cells [18] depolarization after hypoxia and then enhance $\mathrm{Ca}^{2+}$-currents which leading to an increase of intracellular $\mathrm{Ca}^{2+}$, however this step was thought to be prior to the phosphorylation of $\mathrm{Ca}^{2+}$-channel protein. Therefore, in this study, superfusion of ET alone without hypoxia stimulation was not able to induce any changes in the intracelluar $\mathrm{Ca}^{2+}$ levels, nor basal carotid sinus nerve activity. Nevertheless, perfusion CB preparation with ET produced long-lasting dose-dependent increase in Carotid Sinus Nerve (CSN) in normoxic and hypoxic conditions [28]. With this in mind, ET may participate the increase of inward $\mathrm{Ca}^{2+}$ currents posterior to the stimulation of hypoxia and the effect of ET-related chemosensory responses were dependent the presence of vascular control.

In addition to the contribution of ET on inward $\mathrm{Ca}^{2+}$ currents, inflammation that related to ET and ET receptors may also associated with carotid body chemoafferent neuron adaptation process. Previous studies have demonstrated elevated levels of ET-A receptors in resident and invasive CD45+ immune cells distributed in tissue surrounding carotid body chemosensory cell lobules after Chronic Hypoxia $(\mathrm{CH})$ exposure and bosentan, a nonselective ET-A/B receptor antagonist, could blocked the invasion of immune cells and attenuated the upregulation of proinflammatory cytokines consisting of interleukin$1 \beta$ (IL-1 $\beta$ ), interleukin-6 (IL-6), tumor necrosis factor $\alpha$ (TNFa), 
and monocyte chemoattractant protein-1 (MCP-1) [29]. However, Rio shown that $\mathrm{CIH}$-releated potentiation of the $\mathrm{CB}$ chemosensory and ventilatory responses to hypoxia and the hypertension were attributed critically to the oxidative stress whereas TNFa and IL- $1 \beta$ were responsible for the cardio-ventilatory alterations [30]. Reactive Oxygen Species (ROS) were the production of oxidative stress and reports have suggested that ET-1 generated ROS by activating NADPH oxidase [31]. Nevertheless, whether ET-induced generation of ROS could contribute to the enhanced Hypoxic Sensory Response (HSR) in Intermittent Hypoxia ( $\mathrm{IH}$ ) group needs further investigation. What have been confirmed was the fact that ROS play a critical role in $\mathrm{IH}$ induced augmentation of HSR and an increase of basal ET-1 release and upregulation of ETA receptor mRNA in the carotid body which may via ROS-dependent $\mathrm{Ca} 2+$ signaling pathways [32].

$\mathrm{CIH}$ upregulated the expression of Acid-Sensitive Ion Channels (ASICs) in chemoafferent neurons in the petrosal ganglion [29], which was a new discovered cation channels that related to $\left[\mathrm{Ca}^{2+}\right]_{\mathrm{i}}$ in central and peripheral neuronal system [33]. The author also showed that treatment with bosentan blocked the ASICs overexpression, which indicated a possible pathway that was ET involved in the responses to hypoxia conditions [29].

Peng et al. [34] at have shown a long time facilitation of sensory nerve discharge (sLTF) of the carotid body in rodents exposed to $\mathrm{CIH}$ [34], which seemed to be responsible for the elevation of RSNA and hypertension after $\mathrm{CIH}$ exposure [35]. The mechanisms that interpreted the change of the $\mathrm{CB}$ sensory nerve discharge were complicated; however upregulation of ET in the $\mathrm{CIH}$ carotid body was not contributed to sLTF despite its effect on augmented hypoxic sensitivity [36]. Previous studies have confirmed that the SLTF was mediated by Angiotensin II [37] or 5-HT [38] via the common NADPH oxidase-generated ROS system.

\section{The Role of Respiration in the Sympathetic Over Activity after CIH}

Daniel B Zoccal et al. [39] observed a significantly increase of tSNA in late expiration period in $\mathrm{CIH}$ rats compared with normoxic rats [39], and the increase of tSNA was in accordance with an increase of Abdominal Nerve Activity ( $\mathrm{AbN}$ ) at late expiration (late-E) whereas a decrease of cervical nerve and $\mathrm{AbN}$ at post-inspiration period. The increasing response of tSNA during inspiration was similar both in $\mathrm{CIH}$ and normoxia animals.

Similar respiration response after $\mathrm{CIH}$ was also demonstrated in several studies such as enhanced long-term facilitation of respiratory motor activity [40] and an augmented ventilatory response to hypoxia which indicating changes in brainstem respiratory network function after $\mathrm{CIH}$. As we know, cardiovascular sympathetic activity is predominantly regulated through central respiratory activity [41]. Some scholars have discovered that brainstem, where containing neurons involving respiratory-sympathetic coupling and generating respiratory rhythm, related sympathetic nerve activity lasting despite the absence of vagus nerve [42]. A lot of scholars introduced that sympathetic nerve activity emerged accompanied with respiratory cycle [39].

These findings lend credence to the possibility that there present a relationship between sympathetic nerve activity and respiratory action and any stimulation like hypoxia change respiratory rhythm and then alter SNA. As we know, the respiratory response was mainly regulated by chemoreflex that contains peripheral and central components. The cardiorespiratory systems, and their coupling, exhibit an amazing degree of adaptation under physiological e.g. exercise [43], deconditioning
[44], and pathophysiological e.g. heart failure [45] conditions. Herein, any alteration in respiratory activity may lead to sympathetic outflow change.

When any chemical stimulation acts on peripheral chemoreceptor, such as hypoxic condition, glomus cells in the $\mathrm{CB}$ depolarize and release multiple putative neurotransmitters, including acetylcholine, serotonin, ATP, substance P and so on [46], then the afferent information along the carotid body sinus nerve is sent to brainstem firstly integration station, the Nucleus Tractus Solitarius (NTS) [47], activating primary neurons and then the secondary, reaching to other regulating areas such as the RVLM [48], in which containing sympathetic vascularactivated and cardio-sympathetic neurons, inducing contraction in the skin, the kidney, and other vessels but relaxation in important tubes to assure heart and brain possess sufficient blood flow. In this scenario, sympathetic nerve may present overactivity resulting from increased chemoreceptor sensitivity.

\section{Central Respiratory-sympathetic Couples Involved In the Sympathoexcitation}

Central coupling of respiratory and sympathetic neurons may occur at the level of the ventrolateral medulla, where many of the neurons involved in the generation of respiratory and sympathetic activities are located on these domains [49]. Specifically in this region, the inspiratory and expiratory neurons of the Ventral Respiratory Column (VRC) interact with the presympathetic neurons in the RVLM as well as with inhibitory interneurons in the Caudal Ventrolateral Medulla (CVLM) [49]. Sun et al. showing that in sight of anatomical degree, expiratory neurons of ventral respiratory column, which originates from BötC, were projected closely opposed to pre-sympathetic neurons of RVLM along its axon [50]. The pons was also shown to play a significant role in the respiratory modulation of sympathetic nerve activity, since pontine transection conspicuously attenuated this accommodation [51]. In addition, the activities of many medullary and pontine neurons involved in sympathorespiratory functions are modulated by central chemoreceptors located in the RTN/pFRG [52]. RTN/pFRG appears to be an important source of excitation to bulbospinal expiratory neurons located in caudal ventral respiratory column that relay excitatory drive to the lumbar abdominal motoneurons that drive late-E bursting in the $\mathrm{AbN}$ and also to presympathetic RVLM neurons, culminating result in an increase of sympathetic activity correlated with late-E bursts in abdominal motor activity [53]. In a latest study, Moraes et al. [54] shown that the respiratory-modulated RVLM presympathetic neurons may contribute to the increased sympathetic outflow in CIH rats, which mechanisms involve enhanced respiratory synaptic inputs, probably from expiratory neurons.

With respect to the relationship between respiratory action and sympathetic nerve activity, Simms et al. documented that sympathetic overactivity which results from enhanced respiratory-sympatheic coupling was observed in spontaneously hypertensive rats [55]. Central chemoreceptors may be sensitized after $\mathrm{CIH}$ exposure and contribute to the development of active expiratory pattern as well as an augmented sympathetic activity observed in $\mathrm{CIH}$ rats in normoxic/normocapnic conditions [56]. The same authors in this literature also showing that $\mathrm{CIH}$-evoked increase in the neuronal excitability or $\mathrm{CO} 2$ sensitivity results in a lowering of the $\mathrm{CO} 2$ threshold for generation of late- $\mathrm{E}$ activity within the RTN/pFRG.

Peripheral-central chemoreceptor interaction may be involved in the development of plastic changes in the excitability of central chemoreceptors after $\mathrm{CIH}$ conditioning via activation of 
neuromodulators that enhance the activity of RTN chemosensitive neurons, such as serotonin [57], ATP [58], or locally produced oxidative stress [59].

Silva et al. [60] at 2011 have documented that in addition to chemoreflex, other reflexes such as nasopharyngeal and somatosympathetic reflexes also promotes augmented sympathoexcitatory responses after exposured to $\mathrm{CIH}$ conditions [60]. These data indicating that $\mathrm{CIH}$-induced lasting central nervous system changes utilized similar pathways among these reflexes. Maybe these reflexes terminated at RVLM level by activation of glutamatergic neurons, since microinjection of glutamate directly activated RVLM and then evoked exaggerated increases in SNA in rats exposed to $\mathrm{CIH}$ [61].

\section{The Changes of Transmitters on Cerebral Nuclei}

L-glutamate is suggested be the neurotransmitter that released by these viscerosensory primarily afferents in the NTS including those related to cardiovascular baroreceptor and chemoreceptor afferents [62]. Costa et al. [63] manifested the fact that respiratorysympathetic coupling were mediated by glutamatergic inputs in the caudal and intermediate NTS which were activated by chemoreflex [63]. Microinjection L-glutamate into the commissural nucleus tractus solitarius (cNTS) induced thoracic sympathetic nerve (tSN) and central vagus nerve $(\mathrm{cVN})$ activities increase and phrenic nerve $(\mathrm{PN})$ activity decrease, with the changes higher in control than in CIH group [64]. When administrating KYN (a glutamatergic receptor antagonism), the reversing responses compared with L-glutamate were encountered the same tendency in both groups. At the same time, KYN induced decrease in sympathoexcitatory response to peripheral chemoreflex activation in control group but not in $\mathrm{CIH}$ group. With the Western blot analysis showing a significant increase of NMDAR- 1 and glutamate receptor 2/3receptor in cNTS, the author conjecture that $\mathrm{CIH}$ inducing sympathetic and respiratory coupling changes partly resulted from the increased glutamatergic transmission in this position.

Huang et al. [65] demonstrated that $\mathrm{CIH}$ significantly increase renal sympathetic nerve response to intracerebroventricular injection of ET-1 and associated with a higher expression of ETA protein in the subfornical organs [65]. However, whether these changes directly contributed to the sympathic-overactivity after $\mathrm{CIH}$ was needed further investigation.

$\mathrm{CIH}$ in rats promotes increased expression of $\mathrm{c}$-fos, a marker of neuronal activation, in several brainstem regions that are critical for normal regulation of SNA, such as the nucleus of the solitary tract and the ventrolateral medulla [66].

\section{The Role of Baroreflex on the CIH-related Sympathoexcitation}

In addition to peripheral chemoreflex, other reflex that may ultimately influence sympathetic activity involving arterial baroreflex, cardiopulmonary reflex, metaboreflex and so on, coordinated with its central system, produced accommodative changes during $\mathrm{CIH}$ regimen. Baroreflex as a complex regulatory mechanism exhibited unequal responses after $\mathrm{CIH}$ exposure.

Zoccal et al. [67] utilized the sigmoidal analysis found that juvenile rats submitted to $\mathrm{CIH}$ for 10 days exhibited an increased cardiac baroreflex gain [67]. With respect to human patients with obstructive sleep apnea, depressed baroreflex sensitivity was confirmed [68]. A recent study exposed adult rats to $\mathrm{CIH}$ conditions 7 days showing that baroreflex control of RSNA was not attenuated while ABP was increased [69]. Another considerable discovery focused on CIH for 7 days shifts the baroreflex stimulus-response curves of SNA rightward with the midpoint pressure increased $10 \mathrm{mmHg}$, which was in similar magnitude to the increase in resting MAP. These differences were formed possible due to the strain, the use of anesthesia, and the time that exposure to $\mathrm{CIH}$ conditions. However what confirmed was that 7 even 10 days of $\mathrm{CIH}$ induced increased in $\mathrm{ABP}$ was not secondary to reductions in the baroreflex sensitivity and there was a time lag between the development of hypertention and the impairment of baroreflex. Lin et al. demonstrated that after ninety days of $\mathrm{CIH}$, baroreflex-heart response were attenuated, yet heart rate response to cervical vagus nerve electrical stimulus was increased, indicating that the efferent component did not contribute to the impaired baroreflex-heart response [70]. These results indicate a possibility that the baroreflex control of SNA may be reduced after a long term exposure of CIH [71]. Taken together, mechanisms participate in onsetting of hypertention during frontal days of $\mathrm{CIH}$ and the long term sustained increase in $\mathrm{ABP}$ induced by $\mathrm{CIH}$ were different.

\section{The Role of NTS and RVLM in CIH Condition}

As previously proposed, the NTS, RVLM and other cerebral organ make adaptive changes and lead to sympathetic-related response ultimately after $\mathrm{CIH}$.

The afferents of baroreceptor and chemoreceptor integration were terminated at the medial and medial or commissural site of central nervous system. Other previously studies have demonstrated that lesions or inhibition of commissural subnuclei of the nucleus tractus solitarii in the medulla, where $\mathrm{CB}$ chemoreceptors project, reduce blood pressure in spontaneously hypertensive rats [72].

The NTS sends reciprocal projections to several nuclei within the forebrain, brainstem and spinal cord. Prominent areas for innervation include the paraventricular nucleus of hypothalamus, rostral and caudal ventrolateral medulla, and raphé. It is the coordinated activity of the NTS with these other central nuclei that modulates the cardiorespiratory system during hypoxic stress [73].

Kline et al. [74] used caudal NTS cells in the vitro brainstem preparation showing that $\mathrm{CIH}$ augments chemosensory afferent fiber activity, which then contributes to the increased overall activity in NTS cells and the central processing of afferent information accompanied with its associated reflexes [74]. And these enhanced responses were time-dependent and reversible.

RVLM neurons are critical for the maintenance of resting arterial pressure and are important to the sympathoexcitatory response of the chemoreflex. Anatomical and imunohistochemical studies have suggested the existence of a direct excitatory projection from the NTS to the RVLM [75], which may convey peripheral chemoreceptor signals. When peripheral chemoreceptors are stimulated, the RVLM neurons project to the intermediolateral cell column in the spinal cord. Moraes used electrophysiological technique demonstrated that a specific subpopulation of non-cathecholaminergic $\mathrm{C} 1$ respiratory-modulated RVLM presympathetic neurons presented enhanced excitatory synaptic inputs from the respiratory network after $\mathrm{CIH}$ which may contribute to the increased sympathetic activity observed in $\mathrm{CIH}$ rats [54]. Further study will be necessary to delineate the basis and cellular mechanisms of changes to RVLM neurones induced by exposure to CIH.

Several studies in the literature previously support the concept that in the first weeks of life, $\mathrm{CIH}$ is more effective in producing changes in the central nervous system. Ling et al. showed that the long-term facilitation of ventilatory responses is greater in 1-month-old rats than 
Citation: An Q, Ji ES (2014) The Nervous Mechanism of Sympathetic over Activity Induced by Chronic Intermittent Hypoxia. J Pulm Respir Med 4 : 170. doi:10.4172/2161-105X. 1000170

Page 5 of 7

in 2-month-old rats [76]. And the initial 4 weeks of life are important for the maturation of the carotid body and chemoreflex responses, since previously exposure to hyperoxia throughout the period of 1-4 weeks of age result in an attenuation of the ventilatory and phrenic responses to acute hypoxia [77]. Reeves et al. demonstrated that exposure to $\mathrm{CIH}$ during the first 30 days of life exhibited a decrease in the number of neurons that receiving vagal and glossopharyngeal projections in the NTS and nucleus ambiguus in accompany with an augmentation in the number of neurones receiving projections in the RVLM [78]. These crucial anatomical lines of proof underline the concept that alterations within selected brainstem nuclei may develop after $\mathrm{CIH}$ and early postnatal environmental exposures, including $\mathrm{CIH}$, may lead to longterm alterations in cardiorespiratory control [11]

Above all, what definitely is that $\mathrm{CIH}$-induced hypertension is associated with sympathetic nerve system overactivity, and the latter is regulated by several different ways which include peripheral chemoreflex, baroreflex, central system and other regulatory factors like ET-1 and glutamate, notwithstanding these analyses are insufficient to underlie the whole mechanisms that behind the process of $\mathrm{CIH}$-related sympathetic nerve changes. The increased of peripheral chemoreflex sensitivity result in central respiratory activity changes which is characterized by enhanced expiratory response in late expiratory period and increased sympathetic nerve activity during the same period. These changes are adaptive to the hypoxia. With respect to baroreflex, we suppose that long time $\mathrm{CIH}$ may impair its sensitivity whereas several days of exposure exhibit diverse response.

Our laboratory is mainly focus on the role of ET-1 in hypertension after $\mathrm{CIH}$ exposure. In addition to it directly effect on vessel and smooth muscle cell, ET-1 is also involved in oxidize stress response at carotid body or brain. Though the precisely effect of ET-1 on central system that influence sympathetic nerve activity is not absolutely determined, its pressor effect in brain organs is supposed to similar to angiotensin.

$\mathrm{CIH}$-induced sympathetic nerve system changes are diverse with allround mechanisms, attracting a great deal of attention among scholars. The intimate regulatory mechanisms of sympathetic alteration and how these principles interact with each other need further investigation.

\section{Acknowledgements}

This work was supported by grants from the National Natural Science Foundation of China (30971195 and 81170069) and Hebei Province Natura Science Foundation (C2011206031 and C2009001053).

\section{References}

1. Fletcher EC, Lesske J, Behm R, Miller CC 3rd, Stauss H, et al (1992) Carotid chemoreceptors, systemic blood pressure, and chronic episodic hypoxia mimicking sleep apnea. J Appl Physiol (1985) 72: 1978-1984.

2. Fletcher EC, Lesske J, Qian W, Miller CC 3rd, Unger T (1992) Repetitive, episodic hypoxia causes diurnal elevation of blood pressure in rats. Hypertension 19: 555-561.

3. Gilmartin GS, Lynch M, Tamisier R, Weiss JW (2010) Chronic intermitten hypoxia in humans during 28 nights results in blood pressure elevation and increased muscle sympathetic nerve activity. Am J Physiol Heart Circ Physiol 299: H925-931.

4. Huber DA, Schreihofer AM (2013) Altered regulation of sympathetic nerve activity by the caudal ventrolateral medulla in rats after exposure to chronic intermittent hypoxia. The FASEB Journal 27: 699.

5. Fletcher EC, Lesske J, Culman J, Miller CC, Unger T (1992) Sympathetic denervation blocks blood pressure elevation in episodic hypoxia. Hypertension 20: 612-619.

6. Bao G, Metreveli N, Li R, Taylor A, Fletcher EC (1997) Blood pressure response to chronic episodic hypoxia: role of the sympathetic nervous system. J App Physiol (1985) 83: 95-101.
7. Kumar GK, Rai V, Sharma SD, Ramakrishnan DP, Peng YJ, et al. (2006) Chronic intermittent hypoxia induces hypoxia-evoked catecholamine efflux in adult rat adrenal medulla via oxidative stress. J Physiol 575: 229-239.

8. Guild SJ, Barrett CJ, Malpas SC (2005) Long-term recording of sympathetic nerve activity: the new frontier in understanding the development of hypertension? Clin Exp Pharmacol Physiol 32: 433-439.

9. Zoccal DB, Bonagamba LG, Oliveira FR, Antunes-Rodrigues J, Machado BH (2007) Increased sympathetic activity in rats submitted to chronic intermittent hypoxia. Exp Physiol 92: 79-85

10. Braga VA, Soriano RN, Machado BH (2006) Sympathoexcitatory response to peripheral chemoreflex activation is enhanced in juvenile rats exposed to chronic intermittent hypoxia. Exp Physiol 91: 1025-1031.

11. Peng YJ, Prabhakar NR (2004) Effect of two paradigms of chronic intermitten hypoxia on carotid body sensory activity. J Appl Physiol (1985) 96: 1236-1242.

12. Lesske J, Fletcher EC, Bao G, Unger T (1997) Hypertension caused by chronic intermittent hypoxia--influence of chemoreceptors and sympathetic nervous system. J Hypertens 15: 1593-1603.

13. Tamisier R, Gilmartin GS, Launois SH, Pépin JL, Nespoulet H, et al. (2009) A new model of chronic intermittent hypoxia in humans: effect on ventilation, sleep, and blood pressure. J Appl Physiol (1985) 107: 17-24.

14. Peng YJ, Prabhakar NR (2003) Reactive oxygen species in the plasticity of respiratory behavior elicited by chronic intermittent hypoxia. J Appl Physio (1985) 94: 2342-2349

15. Loredo JS, Clausen JL, Nelesen RA, Ancoli-Israel S, Ziegler MG, et al. (2001) Obstructive sleep apnea and hypertension: are peripheral chemoreceptors involved? Med Hypotheses 56: 17-19.

16. Prabhakar NR, Premkumar DRD, Yang T (1999) Hypobaric hypoxia upregulates neuronal and endothelial nitric oxide synthase in the carotid body. FASEB $\mathrm{J} 13$ : A1093.

17. Rubanyi GM, Polokoff MA (1994) Endothelins: molecular biology, biochemistry, pharmacology, physiology, and pathophysiology. Pharmacol Rev 46: 325-415.

18. Rey S, Del Rio R, Iturriaga R (2006) Contribution of endothelin-1 to the enhanced carotid body chemosensory responses induced by chronic intermittent hypoxia. Brain Res 1086: 152-159.

19. Rey S, Del Rio R, Alcayaga J, Iturriaga R (2004) Chronic intermittent hypoxia enhances cat chemosensory and ventilatory responses to hypoxia. J Physio 560: $577-586$

20. Rey S, Del Rio R, Alcayaga J, Iturriaga R (2006) Endothelins in the cat petrosal ganglion and carotid body: effects and immunolocalization. Brain Res 1069 154-158.

21. McQueen DS, Dashwood MR, Cobb VJ, Bond SM, Marr CG, et al. (1995) Endothelins and rat carotid body: autoradiographic and functional pharmacological studies. J Auton Nerv Syst 53: 115-125.

22. Chen J, He L, Dinger B, Stensaas L, Fidone S (2002) Role of endothelin and endothelin A-type receptor in adaptation of the carotid body to chronic hypoxia. Am J Physiol Lung Cell Mol Physiol 282: L1314-1323.

23. Rey S, Corthorn J, Chacón C, Iturriaga R (2007) Expression and immunolocalization of endothelin peptides and its receptors, ETA and ETB, in the carotid body exposed to chronic intermittent hypoxia. J Histochem Cytochem 55: 167-174

24. Wang ZZ, Stensaas LJ, Dinger B, Fidone SJ (1991) Co-existence of tyrosine hydroxylase and dopamine beta-hydroxylase immunoreactivity in glomus cells of the cat carotid body. J Auton Nerv Syst 32: 259-264.

25. Gardner A, Westfall TC, Macarthur H (2005) Endothelin (ET)-1-induced inhibition of ATP release from PC-12 cells is mediated by the ETB receptor differential response to ET-1 on ATP, neuropeptide Y, and dopamine levels. J Pharmacol Exp Ther 313: 1109-1117.

26. Iturriaga R, Alcayaga J (2004) Neurotransmission in the carotid body: transmitters and modulators between glomus cells and petrosal ganglion nerve terminals. Brain Res Brain Res Rev 47: 46-53.

27. Chen J, He L, Dinger B, Fidone S (2000) Cellular mechanisms involved in rabbit carotid body excitation elicited by endothelin peptides. Respir Physiol 121: 13-23.

28. Fidone SJ, Gonzalez C, Almaraz L, Dinger B (1997) Cellular mechanisms of peripheral chemoreceptor function. The Lung: Scientific Foundations: 17251746. 
Citation: An Q, Ji ES (2014) The Nervous Mechanism of Sympathetic over Activity Induced by Chronic Intermittent Hypoxia. J Pulm Respir Med 4 : 170. doi:10.4172/2161-105X. 1000170

Page 6 of 7

29. Liu X, He L, Dinger B, Stensaas L, Fidone S (2012) Effect of Endothelin Receptor Antagonist Bosentan on Chronic Hypoxia-Induced Inflammation and Chemoafferent Neuron Adaptation in Rat Carotid Body. High Altitude Medicine \& Biology 13: 209-216.

30. Rio RD, Moya EA, Iturriaga R (2013) Selective contribution of inflammation and oxidative stress to the cardiorespiratory and carotid body alterations following intermittent hypoxia. The FASEB Journal: $27: 721.1$

31. Dammanahalli KJ, Sun Z (2008) Endothelins and NADPH oxidases in the cardiovascular system. Clin Exp Pharmacol Physiol 35: 2-6.

32. Pawar A, Nanduri J, Yuan G, Khan SA, Wang N, et al. (2009) Reactive oxygen species-dependent endothelin signaling is required for augmented hypoxic sensory response of the neonatal carotid body by intermittent hypoxia. Am J Physiol Regul Integr Comp Physiol 296: R735-742.

33. Hu ZL, Huang C, Fu H, Jin Y, Wu WN, et al. (2010) Disruption of PICK1 attenuates the function of ASICs and PKC regulation of ASICs. Am J Physio Cell Physiol 299: C1355-1362.

34. Peng YJ, Yuan G, Jacono FJ, Kumar GK, Prabhakar NR (2006) 5-HT evokes sensory long-term facilitation of rodent carotid body via activation of NADPH oxidase. J Physiol 576: 289-295.

35. Prabhakar NR, Peng YJ, Kumar GK, Pawar A (2007) Altered carotid body function by intermittent hypoxia in neonates and adults: relevance to recurrent apneas. Respir Physiol Neurobiol 157: 148-153.

36. Peng YJ, Nanduri J, Raghuraman G, Wang N, Kumar GK, et al. (2013) Role of oxidative stress-induced endothelin-converting enzyme activity in the alteration of carotid body function by chronic intermittent hypoxia. Exp Physiol 98: 16201630.

37. Peng YJ, Raghuraman G, Khan SA, Kumar GK, Prabhakar NR (2011) Angiotensin II evokes sensory long-term facilitation of the carotid body via NADPH oxidase. J Appl Physiol (1985) 111: 964-970

38. Peng YJ, Nanduri J, Yuan G, Wang N, Deneris E, et al. (2009) NADPH oxidase is required for the sensory plasticity of the carotid body by chronic intermittent hypoxia. J Neurosci 29: 4903-4910.

39. Zoccal DB, Simms AE, Bonagamba LG, Braga VA, Pickering AE, et al. (2008) Increased sympathetic outflow in juvenile rats submitted to chronic intermittent hypoxia correlates with enhanced expiratory activity. J Physiol 586: 3253-3265.

40. McGuire M, Zhang Y, White DP, Ling L (2003) Chronic intermittent hypoxia enhances ventilatory long-term facilitation in awake rats. J Appl Physiol (1985) 95: 1499-1508

41. Malpas SC (1998) The rhythmicity of sympathetic nerve activity. Prog Neurobio 56: 65-96.

42. Zhong S, Zhou SY, Gebber GL, Barman SM (1997) Coupled oscillators account for the slow rhythms in sympathetic nerve discharge and phrenic nerve activity. Am J Physiol 272: R1314-1324.

43. Michelini LC, Stern JE (2009) Exercise-induced neuronal plasticity in centra autonomic networks: role in cardiovascular control. Exp Physiol 94: 947-960.

44. Hasser EM1, Moffitt JA (2001) Regulation of sympathetic nervous system function after cardiovascular deconditioning. Ann N Y Acad Sci 940: 454-468.

45. Patel KP (2000) Role of paraventricular nucleus in mediating sympathetic outflow in heart failure. Heart Fail Rev 5: 73-86.

46. Bisgard GE (2000) Carotid body mechanisms in acclimatization to hypoxia Respir Physiol 121: 237-246.

47. Segar JL, Smith OJ, Holley AT (1999) Mechano- and chemoreceptor modulation of renal sympathetic nerve activity at birth in fetal sheep. Am J Physiol 276: R1295-R1301.

48. Dampney RA (1994) Functional organization of central pathways regulating the cardiovascular system. Physiol Rev 74: 323-364

49. Guyenet PG (2006) The sympathetic control of blood pressure. Nat Rev Neurosci 7: 335-346.

50. Sun QJ, Minson J, Llewellyn-Smith IJ, Arnolda L, Chalmers J, et al. (1997) Bötzinger neurons project towards bulbospinal neurons in the rostral ventrolateral medulla of the rat. J Comp Neurol 388: 23-31.

51. Baekey DM, Molkov YI, Paton JF, Rybak IA, Dick TE (2010) Effect of baroreceptor stimulation on the respiratory pattern: insights into respiratorysympathetic interactions. Respir Physiol Neurobiol 174: 135-145.
52. Takakura AC, Colombari E, Menani JV, Moreira TS (2011) Ventrolateral medulla mechanisms involved in cardiorespiratory responses to central chemoreceptor activation in rats. Am J Physiol Regul Integr Comp Physiol 300: R501-510.

53. Molkov YI, Abdala AP, Bacak BJ, Smith JC, Paton JF, et al. (2010) Lateexpiratory activity: emergence and interactions with the respiratory $\mathrm{CpG}$. J Neurophysiol 104: 2713-2729.

54. Moraes DJ, da Silva MP, Bonagamba LG, Mecawi AS, Zoccal DB, et al. (2013) Electrophysiological properties of rostral ventrolateral medulla presympathetic neurons modulated by the respiratory network in rats. J Neurosci 33: 1922319237.

55. Simms AE, Paton JF, Pickering AE, Allen AM (2009) Amplified respiratorysympathetic coupling in the spontaneously hypertensive rat: does it contribute to hypertension? J Physiol 587: 597-610.

56. Molkov YI, Zoccal DB, Moraes DJ, Paton JF, Machado BH, et al. (2011) Intermittent hypoxia-induced sensitization of central chemoreceptors contributes to sympathetic nerve activity during late expiration in rats. J Neurophysiol 105: 3080-3091.

57. Mulkey DK, Rosin DL, West G, Takakura AC, Moreira TS, et al. (2007) Serotonergic neurons activate chemosensitive retrotrapezoid nucleus neurons by a $\mathrm{pH}$-independent mechanism. J Neurosci 27: 14128-14138.

58. Mulkey DK, Mistry AM, Guyenet PG, Bayliss DA (2006) Purinergic P2 receptors modulate excitability but do not mediate $\mathrm{pH}$ sensitivity of RTN respiratory chemoreceptors. J Neurosci 26: 7230-7233.

59. Jurado-Gámez B, Fernandez-Marin MC, Gómez-Chaparro JL, Muñoz-Cabrera L, Lopez-Barea J, et al. (2011) Relationship of oxidative stress and endothelia dysfunction in sleep apnoea. Eur Respir J 37: 873-879.

60. Silva AQ, Schreihofer AM (2011) Altered sympathetic reflexes and vascula reactivity in rats after exposure to chronic intermittent hypoxia. J Physiol 589: 1463-1476.

61. McGuire M, Bradford A (1999) Chronic intermittent hypoxia increases haematocrit and causes right ventricular hypertrophy in the rat. Respir Physio 117: 53-58.

62. Gordon FJ, Sved AF (2002) Neurotransmitters in central cardiovascular regulation: glutamate and GABA. Clin Exp Pharmacol Physiol 29: 522-524.

63. Costa-Silva JH, Zoccal DB, Machado BH (2010) Glutamatergic antagonism in the NTS decreases post-inspiratory drive and changes phrenic and sympathetic coupling during chemoreflex activation. J Neurophysiol 103: 2095-2106.

64. Costa-Silva JH, Zoccal DB, Machado BH (2012) Chronic intermittent hypoxia alters glutamatergic control of sympathetic and respiratory activities in the commissural NTS of rats. Am J Physiol Regul Integr Comp Physiol 302: R785793.

65. Huang J, Xie T, Wu Y, Li X, Lusina S, et al. (2010) Cyclic intermittent hypoxia enhances renal sympathetic response to ICV ET-1 in conscious rats. Respi Physiol Neurobiol 171: 83-89.

66. Greenberg HE, Sica AL, Scharf SM, Ruggiero DA (1999) Expression of c-fos in the rat brainstem after chronic intermittent hypoxia. Brain Res 816: 638-645.

67. Zoccal DB, Bonagamba LGH, Paton JFR, Machado1 BH (2009) Sympatheticmediated hypertension of awake juvenile rats submitted to chronic intermittent hypoxia is not linked to barore ex dysfunction. Exp Physiol 94: 972-983.

68. Carlson JT, Hedner JA, Sellgren J, Elam M, Wallin BG (1996) Depressed baroreflex sensitivity in patients with obstructive sleep apnea. Am J Respir Crit Care Med 154: 1490-1496.

69. Yamamoto K, Eubank W, Franzke M, Mifflin S (2013) Resetting of the sympathetic baroreflex is associated with the onset of hypertension during chronic intermittent hypoxia. Auton Neurosci 173: 22-27.

70. Lin M, Liu R, Gozal D, Wead WB, Chapleau MW, et al. (2007) Chronic intermittent hypoxia impairs baroreflex control of heart rate but enhances heart rate responses to vagal efferent stimulation in anesthetized mice. Am J Physio Heart Circ Physiol 293: H997-1006.

71. Peng YJ, Nanduri J, Zhang X, Wang N, Raghuraman G, et al. (2012) Endothelin-1 mediates attenuated carotid baroreceptor activity by intermittent hypoxia. J Appl Physiol (1985) 112: 187-196.

72. Sato MA, Colombari E, Morrison SF (2002) Inhibition of neurons in commissural nucleus of solitary tract reduces sympathetic nerve activity in SHR. Am J Physiol Heart Circ Physiol 282: H1679-1684. 
Citation: An Q, Ji ES (2014) The Nervous Mechanism of Sympathetic over Activity Induced by Chronic Intermittent Hypoxia. J Pulm Respir Med 4: 170. doi:10.4172/2161-105X. 1000170

73. Kline DD (2008) Plasticity in glutamatergic NTS neurotransmission. Respir Physiol Neurobiol 164: 105-111.

74. Kline DD, Ramirez-Navarro A, Kunze DL (2007) Adaptive depression in synaptic transmission in the nucleus of the solitary tract after in vivo chronic intermittent hypoxia: evidence for homeostatic plasticity. J Neurosci 27: 4663-4673.

75. Urbanski RW, Sapru HN (1988) Putative neurotransmitters involved in medullary cardiovascular regulation. J Auton Nerv Syst 25: 181-193.
76. McGuire M, Ling L (2005) Ventilatory long-term facilitation is greater in 1- vs. 2-mo-old awake rats. J Appl Physiol (1985) 98: 1195-1201.

77. Bisgard GE, Olson EB Jr, Wang ZY, Bavis RW, Fuller DD, et al. (2003) Adult carotid chemoafferent responses to hypoxia after 1,2 , and 4 wk of postnatal hyperoxia. J Appl Physiol (1985) 95: 946-952.

78. Reeves SR, Guo SZ, Brittian KR, Row BW, Gozal D (2006) Anatomical changes in selected cardio-respiratory brainstem nuclei following early postnatal chronic intermittent hypoxia. Neurosci Lett 402: 233-237. 